\title{
GOOGLE EARTH ENGINE BASED AGRICULTURAL DROUGHT MONITORING IN KODAVANAR WATERSHED, PART OF AMARAVATHI BASIN, TAMIL NADU, INDIA
}

\author{
Commission V, Youth Forum
}

Periasamy Thilagaraj, Palanisamy Masilamani*, Ravichandran Venkatesh, Jothiramalingam Killivalavan

Department of Geography, Bharathidasan University, Tiruchirappalli, Tamil Nadu, India.

(pthilagaraj23@gmail.com,masilamani.ap@gmail.com, venkatvejef007@gmail.com,muralikilli11@gmail.com)

KEY WORDS: Drought, Google Earth Engine, Vegetation Health Index, Standardized, Precipitation Index, Kodavanar.

\begin{abstract}
:
The agricultural drought assessment and monitoring has become a prime concern in recent times as it impedes land capability and causes food scarcity. Therefore, the present study constructed a methodological framework through the Google Earth Engine (GEE) platform, which offers advanced and effective monitoring in a timely concern of the drought occurrences. The study has been carried out in the Kodavanar watershed, a part of the Amaravathi basin is noted with signs of drought such as insufficient rainfall and vegetation stress in the current situation. The remote sensing indices are utilised for the agriculture drought assessment including Land Surface Temperature (LST), Normalized Difference Vegetation Index (NDVI), Temperature Condition Index (TCI), Vegetation Condition Index (VCI) and Vegetation Health Index (VHI). In particular, the VHI results show that the area of healthy vegetation and no drought category is rapidly decreased from 934.29 to 107.83 sq.km across the years and have been reached threatening condition as extreme drought category with extremely low vegetation cover has been increasing in a exponential proportion of over 5\% in the year 2019 and 2020. However, the agriculture drought results compared through the meteorological drought indicator of Standardized Precipitation Index (SPI) reflects that the SPI and VHI are reflecting similar signs and indicating the dry condition of precipitation with moderate vegetation over the highlighted regions of northern tip and central eastern portions. This present work illustrates the effective use of the GEE platform in monitoring the agriculture drought and the highlighted portions of the study should be implemented with proper water resource management by the researchers, planners and policymakers in the Kodavanar watershed for reducing the vegetation stress.
\end{abstract}

\section{AGRICULTURAL DROUGHT MONITORING}

\subsection{Introduction}

Drought is a naturally occurring climatic phenomenon that impacts human, environmental activity and several sectors of the economy worldwide and noted to be one of the highest and widespread forms of natural hazard. Eventually, it is experienced by the extremely dry condition that prevails over a longer period and will harm the vegetation (Wilhite et al., 2007). Moreover, its temporal occurrence impedes the reduction in the capability of the land towards crop production and make the inhospitable condition to all the livestock and human being (Siddiqui, 2004). In India, the meteorological and agricultural drought is common in recent decades due to the monsoon failure and inadequate precipitation which renders socioeconomic impact over many parts of the country (Chand \& Raju, 2009). This will have a direct effect on food production and the agricultural economy and an indirect effect on power generation, water supply and industrial growth. Accordingly, Agricultural drought has a severe effect on the global level which decrease food production and increase the demand for food (Deryng et al., 2014). Due to its severe effect on the productivity of rain-fed crops and indirect effect on employment as well as per capita income, agricultural drought has become a prime concern in worldwide. The occurrence of drought is mainly a climatic phenomenon that cannot be eliminated. However, its effective monitoring and management are possible in reducing impacts in the form of preparedness if actual spatiotemporal information related to crop status is available to the decision-makers (Patel and Yadav, 2015). Accordingly, in the present study, the Kodavanar watershed part of the Amaravathi basin is selected as the study region which is noticed with declined surface soil moisture hindered due to change in rainfall pattern and extreme temperature anomalies. These are signs of drought occurrences, which must be effectively monitored regarding agricultural stress and must be managed with proper management strategies.

The methodology adopted to construct a strong framework in monitoring and assessing the agricultural drought in a web platform (i.e., Google Earth Engine). Google Earth Engine (GEE) is a cloud-based web architecture in geospatial processing. It contains a huge catalogue of satellite imagery of different space agency and various types of geoprocessing tool for public domine (Sazib et al., 2018; Rahaman \& Venkatesh, 2020; Khan \& Gilani 2021). The main significance of GEE is time saving and quick processing. With the access of Landsat 8 OLI, Sentinel 2 Level-1 TOA reflectance and TRMM Monthly Precipitation datasets from earth engine library, the Spatiotemporal drought monitoring, and assessment is carried out for the consecutive five years (2016-2020). Primarily, annual Normalized Vegetation Condition Index (NDVI); Land Surface Temperature (LST) is computed and Vegetation Condition Index (VCI); Temperature Condition Index (TCI) is extracted with a time series map of NDVI and LST. Furthermore, Vegetation Health Index (VHI) is the combination of vegetative nature (VCI) and temperature state (TCI). The actual vegetation condition is illustrated by VCI, but the vegetative health is determined by VHI (vegetation interaction with temperature). VHI has calculated for the whole Kodavanar watershed using the long-term Vegetation Condition Index (VCI) and Temperature Condition Index (TCI) which reveals the occurrence of drought-related vegetative stress. Standardized Precipitation Index (SPI) is calculated with ground measured daily rainfall and Precipitation Condition Index (PCI) from

\footnotetext{
* Corresponding author
} 
satellite measured monthly TRMM 3B43 and correlation were done for ground-based rainfall measurement (SPI) and Vegetation Health Index (VHI). Eventually, the temporal analysis reveals the frequency and intensity of vegetative stress, which helps to acquire a stronger understanding of the pattern of drought and useful in computing a potential agricultural drought in the study region. Then it will be correlated with meteorological phenomena to validate the vegetative stress. Thus, VHI values of normal and drought year were examined and compared with the Standardized Precipitation Index (SPI). Accordingly, a potential area of drought has been defined to monitor and manage for future development. Therefore, the study attempts to give key knowledge on the study area of the Kodavanar watershed which will help the policymakers to develop new management and conservation techniques sustainably.

\section{STUDY AREA}

\subsection{Locational Setting}

Kodavanar watershed part of Amaravathi basin is selected as the study region situated in the southwestern part of Tamil Nadu with the spatial extent of North latitudes from $10^{\circ} 11^{\prime} 37^{\prime \prime}$ to $10^{\circ}$ $27^{\prime} 30$ " and East longitude from $77^{\circ} 377^{\prime} 46$ to $78^{\circ} 01^{\prime} 10^{\prime \prime}$ (Figure 1). Kodavanar watershed lies in the Dindigul district and a minor portion in the Karur district, where it covers a total area of about 2254 sq. $\mathrm{km}$. Topographically, the hilly region is marked $1350 \mathrm{~m}$ above sea level and the plain region are observed between 360 to $120 \mathrm{~m}$. The Kodavanar River originates in Pandrimalai and Sirumalai Hills, situated in the south of Dindigul District, flows towards the north direction and joins Amaravathi mainstream in the southern part of Karur. The mean annual rainfall ranges from 480 to $1880 \mathrm{~mm}$. The major soil type is black and red soil which is further categorised as loamy sand, sandy loamy and clay in which loamy sand is the dominantly characterized soil type. The landuse/land cover infers that cropland is a major class and is rapidly changing as barren land. The study area is well connected with roadway and railway transport. Rice, sugarcane, sorghum, cotton, pulses and oilseeds are the major crops and plantation crops such as mango, pomegranate and tamarind are cultivated in some parts of the study area.

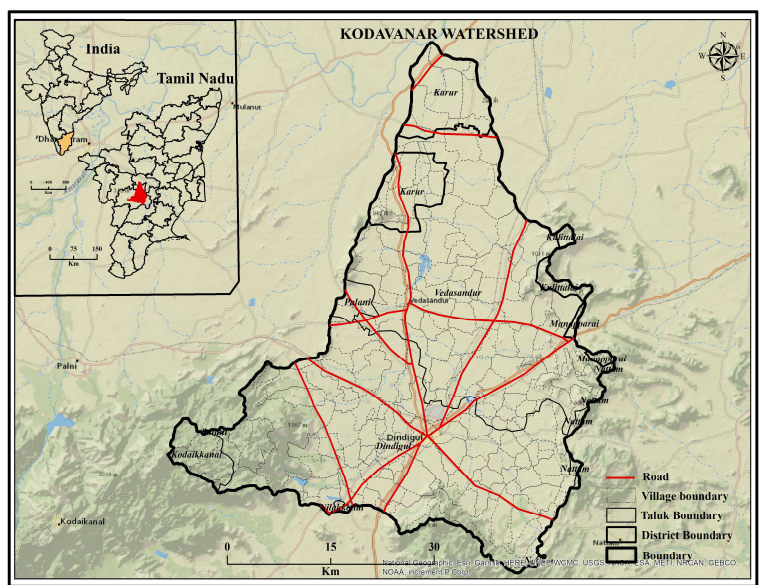

Figure 1: Location of Kodavanar watershed, Tamil Nadu-India

\subsection{Landuse/Landcover}

Support Vector Machine (SVM) classifier have been used to map level-1 landuse/landcover of the study region through
GEE. The Kodavanar watershed classified into twelve classes such as closed forest-evergreen needle leaf, closed forestevergreen broadleaf, closed forest-deciduous broadleaf, open forest-evergreen broadleaf, open forest-deciduous broadleaf, shrubs, herbaceous vegetation, cultivated and managed vegetation/agriculture, built up, bare/sparse vegetation, permanent water bodies and herbaceous wetland shown in Figure 2. In which agriculture land is the predominant land use class and in the southern part of the study area, there is more forest cover which corresponds to the Pandrimalai and Sirumalai hills. Dindigul is the major city present in the southern part of the study region.

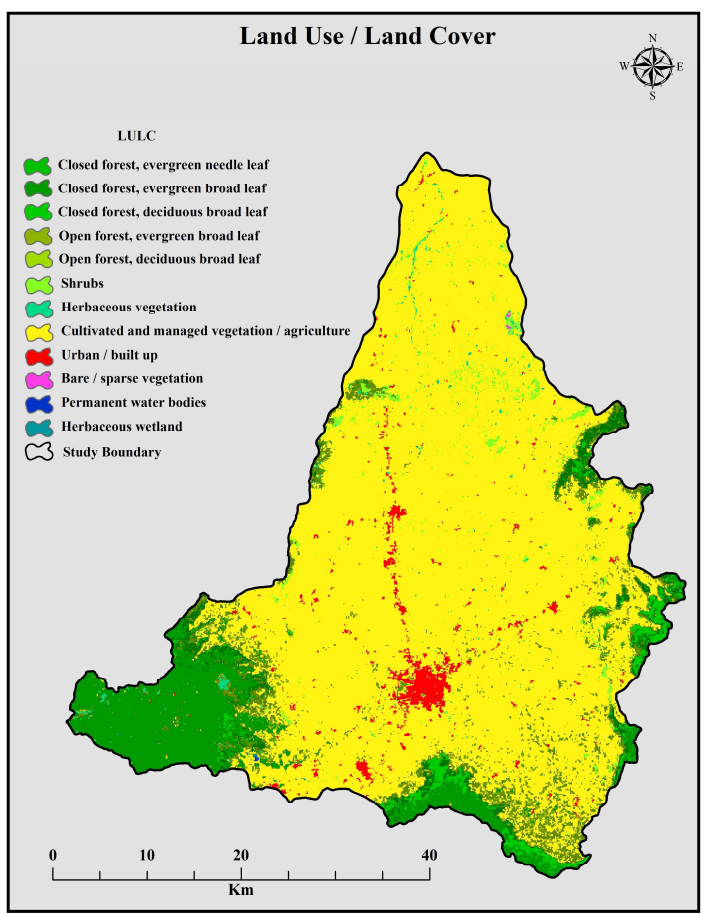

Figure 2: Landuse/Landcover of Study Region

\section{DATA AND METHODOLOGY}

The methodology is framed to compute the agricultural drought condition through various remote sensing indices. The seven drought indices (Table 1) were computed at an annual time scale (i.e., 2016-2020). Each index has been derived following the drought scale and mapped to assess the drought intensity in the study region.

\subsection{Satellite-Based Drought Indices}

All the drought indices are computed with the utilisation of remote sensing data product. In the Landsat 8 OLI/TIRS data (USGS Landsat 8 Surface Reflectance Tier 1) optical and thermal band were used to compute a Normalized Difference Vegetation Index (NDVI) and Land Surface Temperature (LST) through the formula mentioned in Table 1. Then Vegetation Condition Index (VCI) and Temperature Condition Index (TCI) is computed through time series NDVI and LST reflectance values. Both the index reflects the drought intensity with the associate drought intensity scale. Finally, Vegetation Health Index (VHI) is extracted for the consecutive year (2016-2020) with help of VCI and TCI. Satellite-based Precipitation Condition Index (PCI) is computed through TRMM 3B42: 3Hourly Precipitation Estimates data and Standardized Precipitation Index (SPI) have been computed based on the 
ground measured rainfall data. Copernicus Global Land Cover Layers: CGLS-LC100 collection 3 is utilised to map the landuse/landcover.

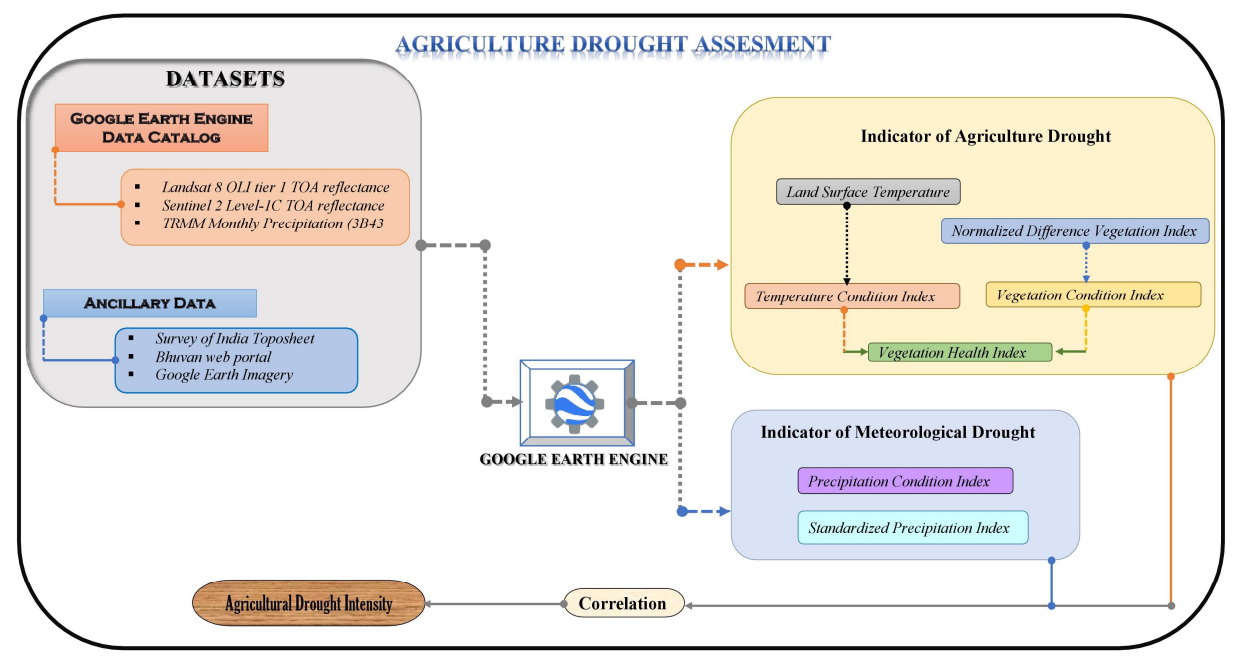

Figure 3: Methodological Framework for Agriculture Drought Assessment

Table 1: Drought Indices Utilised for the Study

\begin{tabular}{|c|c|c|}
\hline Indices & Formula & Reference \\
\hline SPI & $\frac{\left(X i j-X_{i m}\right)}{\sigma}$ & $\begin{array}{l}\text { (Livada \& } \\
\text { Assimakopoulos, } \\
\text { 2007) }\end{array}$ \\
\hline NDVI & $\frac{(N I R-r e d)}{(N I R+r e d)}$ & $\begin{array}{l}\text { (Kogan et al., } \\
\text { 2003; Venkatesh et } \\
\text { al., 2020) }\end{array}$ \\
\hline LST & $\begin{array}{l}\text { 1. Digital Numbers to spectral } \\
\text { radiance } \\
\mathrm{L} \lambda=\mathrm{ML} * \mathrm{Qcal}+\mathrm{AL} \\
\text { 2. Spectral radiance to } \\
\text { brightness temperature } \\
\mathrm{BT}=\mathrm{K} 2 / \ln (\mathrm{k} 1 / \mathrm{L} \lambda+1)- \\
273.15 \\
\text { 3. Proportion of Vegetation } \\
P V=\left[\frac{\left(N D V I-N D V I_{\min }\right)}{\left(N D V I_{\max }-N D V I_{\min }\right)}\right]^{2} \\
\text { 4. Land Surface Emissivity } \\
\mathrm{LSE}=0.004 * \mathrm{PV}+0.986 \\
\text { 5. Land Surface Temperature } \\
\mathrm{LST}=(\mathrm{BT} / 1)+\mathrm{W} *(\mathrm{BT} / \\
\quad 14380) * \ln (\mathrm{LSE})\end{array}$ & $\begin{array}{l}\text { (Chander et al., } \\
\text { 2009; Sobrino et } \\
\text { al., 2004) }\end{array}$ \\
\hline VCI & $\frac{\left(N D V I-N D V I_{\min }\right)}{\left(N D V I_{\max }-N D V I_{\min }\right)}$ & $\begin{array}{l}\text { (Kogan et al., } \\
\text { 2003) }\end{array}$ \\
\hline TCI & $\frac{\left(L S T_{\max }-L S T\right)}{\left(L S T_{\max }-L S T_{\min }\right)}$ & $\begin{array}{l}\text { (Unganai \& } \\
\text { Kogan, 1998) }\end{array}$ \\
\hline PCI & $\frac{\left(T R M M_{\left.-T R M M_{\min }\right)}\right.}{\left(T R M M_{\max }-T R M M_{\min }\right)}$ & (Yu et al., 2019) \\
\hline VHI & $\alpha V C I+(1-\alpha) T C I$ & (Sun et al., 2020) \\
\hline
\end{tabular}

\subsection{Earth Engine Data Processing}

In the field of GIS, Google Earth Engine (GEE) is an advanced cloud-based platform to process all kind of spatial data in a quick time frame (Sun et al., 2020; Rahaman \& Venkatesh, 2020). The GEE will work in JavaScript and Python streamline, likewise in this study all the data have been processed in GEE through JavaScript API. Where the required dataset is extracted from the earth engine data catalogue (i.e., ee.ImageCollection) and drought indices mentioned in Table 1 are computed. In the GEE platform, many functions (i.e., "Map.", "filterDate", "reduce", ".clip", ".print", ".expression", "Export.") are used to import, filter, resample the satellite data, generate the drought indices and export the derived results with common scale and projection system. Further, those exported results are mapped to study the spatio-temporal drought intensity.

For agriculture drought assessment, annual NDVI and LST were generated for the consecutive year (2016-2020) and the minimum and maximum reflectance value of NDVI and LST is extracted to compute annual VCI and TCI. Similarly, VHI is computed with the reflectance value of VCI and TCI. In meteorological drought assessment, SPI is computed by utilizing daily rainfall data acquired from the Indian Meteorological Department (IMD) and PCI is computed using satellite-based precipitation data (TRMM 3B42) for the same period. The detailed methodology is explained in Figure 3.

\section{RESULT AND DISCUSSION}

The agricultural drought is identified for the Kodavanar watershed by deriving the Vegetation Health Index (VHI). However, it requires the input indicators like Temperature Condition Index (TCI) and Vegetation Condition Index (VCI). Further, These TCI and VCI calculation involves the generation of Land Surface Temperature (LST) and Normalized Difference Vegetation Index (NDVI). Eventually, the result of agricultural drought is compared with the meteorological indicator of Standardized Precipitation Index (SPI). All those agricultural and meteorological indicators of drought have been processed, derived and mapped through Google Earth Engine (GEE) which is discussed below. 


\subsection{Land Surface Temperature (LST)}

The LST is one of the significant factors in assessing the agricultural drought as the frequent anomalies in the climate and the rapid increase in the temperature would harm the vegetation. The annual LST is calculated for the years 2016-2020 and has been categorised into five classes as very low $(<20)$, low $(21$ $25)$, moderate (26-30), high (31-35) and very high $(>35)$ shown in figure 4 . The high category of (31-35) temperature is predominant over the study region throughout the years of 2016-2020 and is especially showing high intensity in the year 2018 covering three fourth area of the Kodavanar watershed. Then the very high category of $(>35)$ temperature is marked only in the year 2017 and is distributed over the peripheral parts of the Dindigul city region. Then, the elevated portions of the Pandrimalai and Sirumalai hills fall under very low $(<20)$ and low (21-25) temperature where the vegetation is still a predominant landcover class.

\subsection{Normalized Difference Vegetation Index (NDVI)}

The NDVI values correspond to the vegetation cover and have a direct relationship with the vegetation condition and the vegetation health. Therefore, the annual NDVI is derived for the Kodavanar watershed at the spatio-temporal scale of 2016-2020 and considered a major indicator for agricultural drought assessment. These NDVI values are distributed from 0 to 1 and have been categorised into 6 classes as very high $(>0.8)$, high (0.6-0.8), moderate $(0.4-0.6)$, low $(0.2-0.4)$, very low $(0-0.2)$ and bare soil/waterbodies $(<0)$ shown in Figure 5. The very high and high NDVI classes are only marked over the parts of Pandrimalai and Sirumalai hills where the rest of the portions in the study region is covered with low and very low vegetation cover. Especially, the bare soil, very low NDVI classes show high intensity in the south-central portion which corresponds to the Dindigul city region and about the low NDVI classes, it is the predominant class distributed over the Kodavanar watershed throughout the years from 2016-2020.

\subsection{Temperature Condition Index (TCI)}

The TCI is the widely used index in drought assessment studies as the temperature plays a major role in identifying the drought occurrence. Here, the annual TCI is obtained for the years from 2016 to 2020 and has been categorised into five classes as no drought $(>40)$, slight drought (31-40), moderate drought (21$30)$, high drought $(11-20)$ and extreme drought $(<10)$ shown in Figure 6 . The TCI values will have indirect relation with the drought as the TCI values decreases, the degree of drought scale will become high. As like as the LST values the TCI values is also showing no drought class only in the parts of Pandrimalai and Sirumalai hills. The spatio-temporal analysis of TCI represents that the high and extreme drought condition is mostly marked intense distribution throughout the study area during 2018 whereas in 2016 and 2019 it is found high concentration over the northern portion.

\subsection{Vegetation Condition Index (VCI)}

The VCI is an important indicator that shows the vegetation condition prevails over the study region and is responsible for assisting the drought condition. The annual $\mathrm{VCI}$ are derived for the years 2016-2020 and the VCI values are categorised into five classes as extreme drought $(<10)$, high drought $(11-20)$, moderate drought (21-30), slight drought (31-40) and no drought $(>40)$ shown in Figure 7. The spatio-temporal analysis of the annual VCI represents that vegetation is reducing across the years at a gradual level and attained extreme drought condition in the year 2020. In the year 2016, the high VCI class of (11-20) is marked only in northern portion with some minor distribution in the middle and southern portions, while in the year 2017 and 2018 the area of this high VCI class developed over the middle and southern portion. Moreover, during the year 2019 , almost the entire portion of the study region except for the elevated regions in the southern portion are covered with high drought class. Especially, in the year 2020, the extreme drought condition is more concentrated over the northern tip of the study region and the high drought region of the previous years have been rapidly converting as extreme drought class.

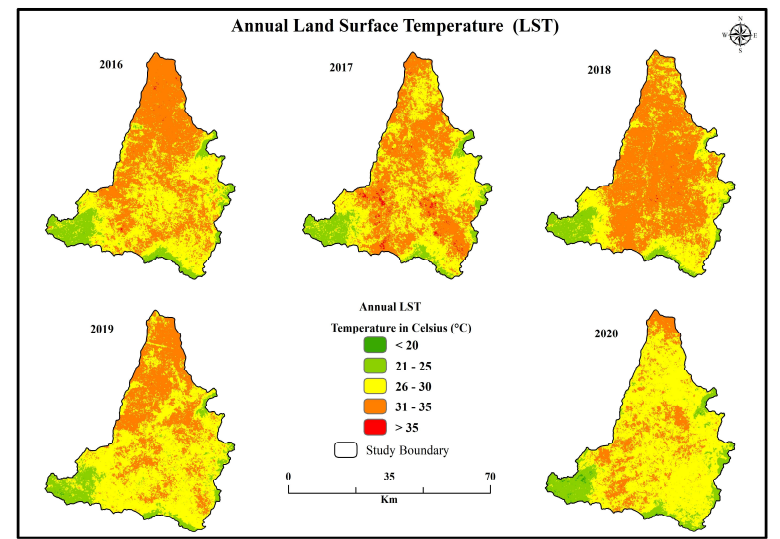

Figure 4: Annual Land Surface Temperature of 2016 to 2020

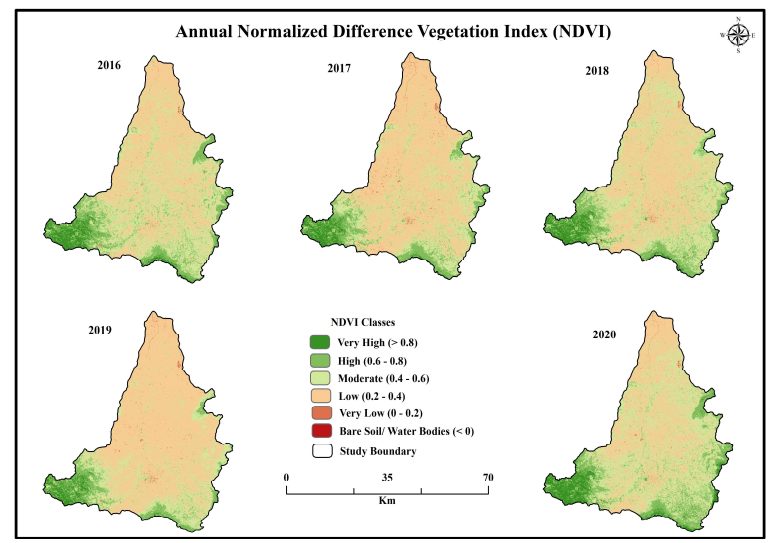

Figure 5: Annual Normalized Difference Vegetation Index of 2016 to 2020

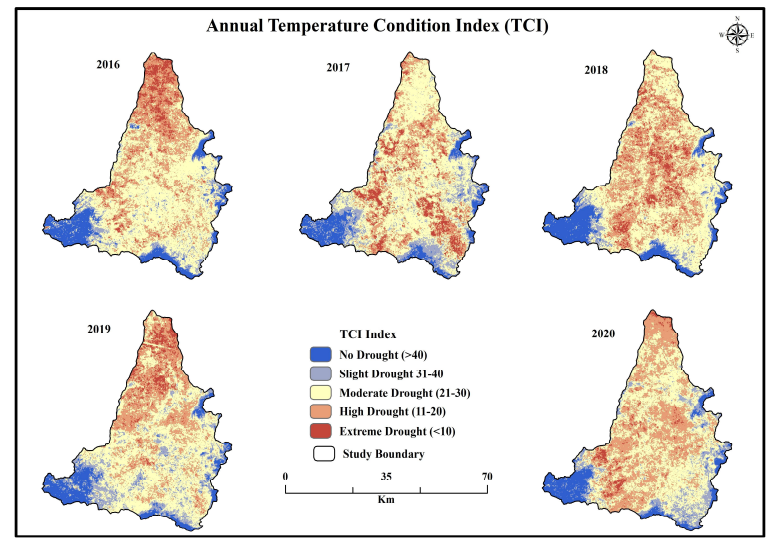

Figure 6: Annual Temperature Condition Index of 2016 to 2020 


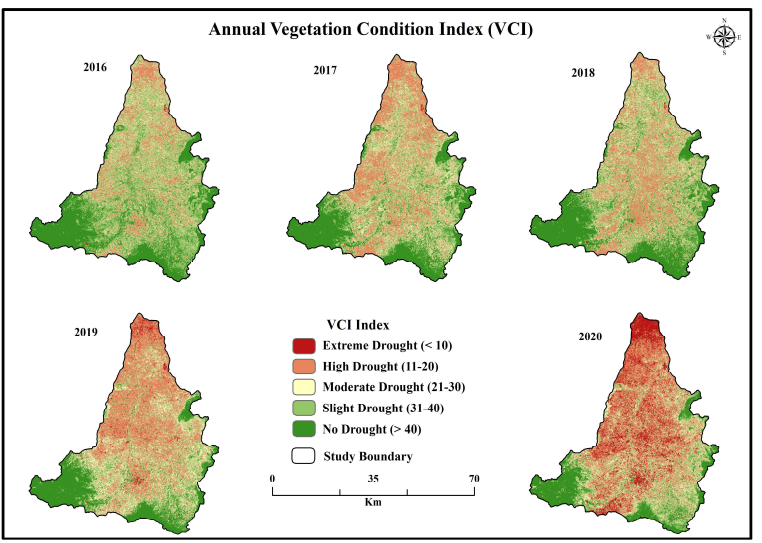

Figure7: Annual Vegetation Condition Index of 2016 to 2020

\subsection{Vegetation Health Index (VHI)}

The values of VHI will directly correspond to the agricultural drought occurrence and is derived by computing both the VCI and TCI values. It is significant in representing the healthy vegetation and vegetation stress prevails in the study region. The VHI values have been categorised into five classes as extreme drought $(<10)$, high drought $(11-20)$, moderate drought (21-30), slight drought (31-40) and no drought (>40) shown in Figure 8. The spatio-temporal analysis of the annual VHI has been calculated from 2016-2020. It represents that the vegetation stress has been gradually increasing from 2016 and becomes predominant over the year 2020 with highly intensified VHI class of extreme drought condition $(<10)$. The distribution of healthy vegetation in the year 2016 is decreased consistently in the consecutive years till 2020. Especially, in the year 2019 and 2020 the distribution of extreme drought $(<10)$, high drought (11-20) VHI class is found to be covering the major portions of the study region. Particularly in the year 2020, the healthy vegetation (slight drought 31-40 and no drought $>40$ ) of the Kodavanar watershed is found only in the Pandrimalai and Sirumalai hills region rather the extreme to high drought covers much of the portions.

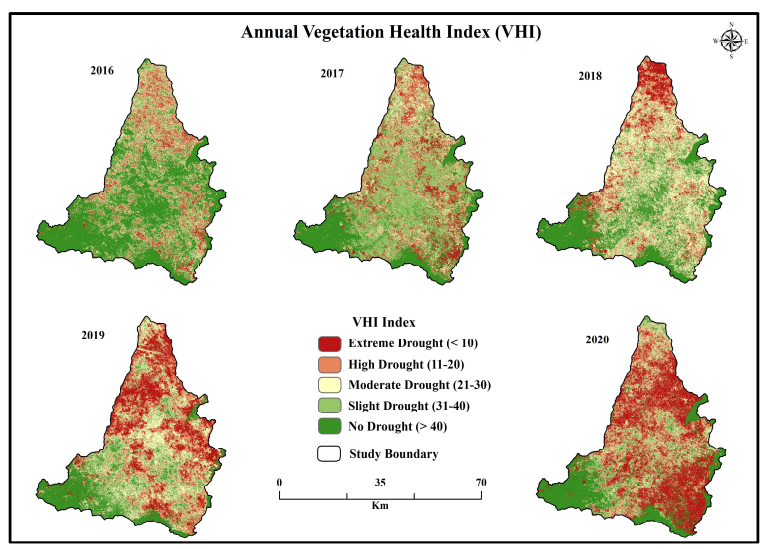

Figure 8: Annual Vegetation Health Index of 2016 to 2020

\subsection{Precipitation Condition Index (PCI)}

In meteorological drought analysis, PCI is considered as the prime concern as it directly corresponds to the precipitation level of the study region. These PCI values are categorised into five classes from no drought to extreme drought like VHI classes. Here, the spatio-temporal analysis of the PCI reveals that the pattern of precipitation is unusual and doesn't follow any patterns shown in Figure 9. The no drought PCI class is distributed mostly in the southern and southeastern portion of 2016 to 2020 except the year 2017, where the no drought class also seems to be distributed over the northern tip of the study region. In the consecutive years from 2016-2020, the extreme drought PCI class is mostly concentrated in the middle and northern portions except the year 2017. Further, the high and moderate PCI class covers the major portion of the Kodavanar watershed throughout the study period.

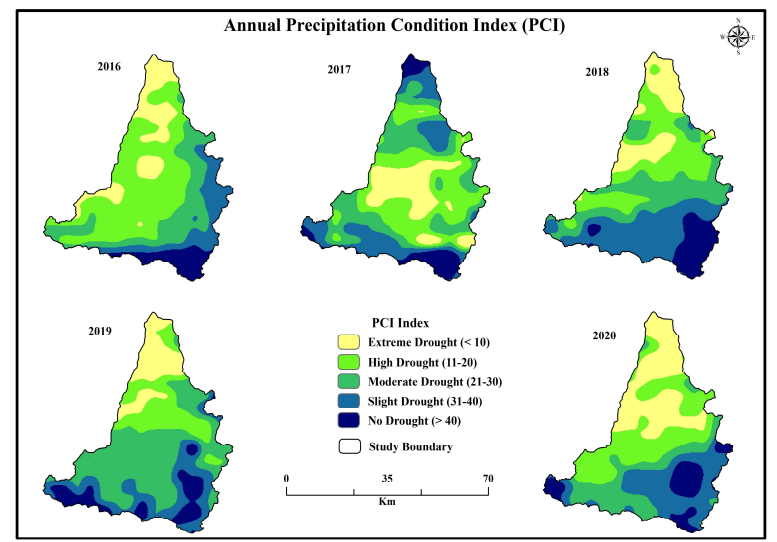

Figure 9: Annual Precipitation Condition Index of 2016 to 2020

\subsection{Standardized Precipitation Index (SPI)}

This SPI is the standardized indicator, which would be observed on account of analysing the meteorological drought occurrences. The SPI values will reflect the climatic anomalies precisely as it is calculated for the 30 years of time interval, and here in this study temporal changes of five consecutive years (2016-2020) is computed. It has been classified into seven classes, such as extremely dry $(\leq 2)$, severely dry $(-1.5$ to -1.99$)$, moderately dry (-1.0 to 1.49$)$, near normal (-0.99 to 0.99$)$, moderately wet (1.0 to 1.49$)$, very wet $(1.5$ to 1.99$)$ and extremely wet $(\geq 2.0)$ (Figure 10$)$. The extremely dry $(\leq 2)$ condition of SPI class is mostly seen in northern tip of the study region and the severely dry (-1.5 to -1.99$)$ class is distributed over the northern, central and middle easter portions from 2016 through 2020. The spatio-temporal changes of SPI interpret that most of the southern region which falls under the hilly terrain of Pandrimalai and Sirumalai hills are marked with moderately dry ( -1.0 to 1.49$)$ to extremely wet $(\geq 2.0)$ category. Initially, in the years 2016 and 2017 the Dindigul city region is distributed with moderately and severely dry class and later it falls under near normal to moderately wet during the years 2018-2020.

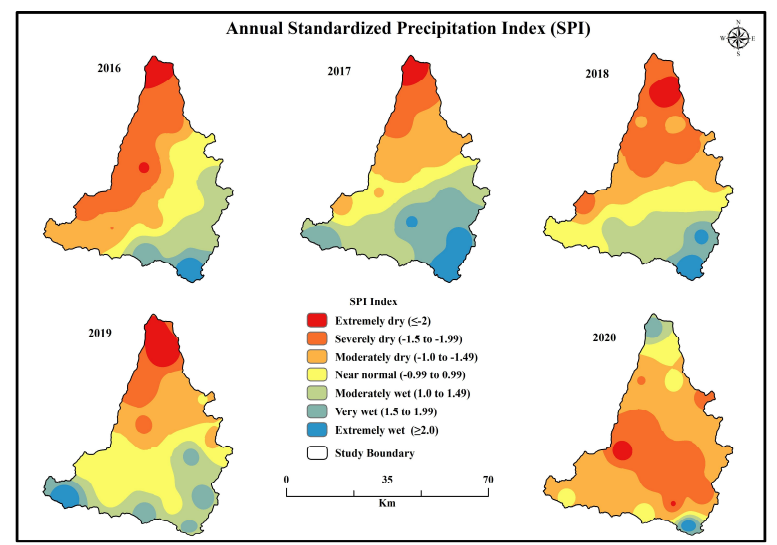

Figure 10: Annual Standardized Precipitation Index of 2016 to 2020 


\subsection{Agricultural Drought Assessment}

The drought assessment is usually analysed in the aspects of agricultural, hydrological and meteorological attributes. In the present study, the assessment of agricultural drought is the major objective, whereas the meteorological drought is also computed to compare with the results of agricultural drought. The initial analysis of the LST and NDVI results shows that most of the regions of the Kodavanar watershed come under the low, very low category of NDVI and moderate-high category of LST. Accordingly, the TCI and VCI values illustrate that the extreme and high drought condition is intensified mostly in the northern region and some of the minor portion of central regions covering the peripheral portions of the Dindigul city region. Especially, the no drought and slight drought category of TCI and VCI values are only marked in the elevated southern region that to particularly in the Pandrimalai and Sirumalai hills.

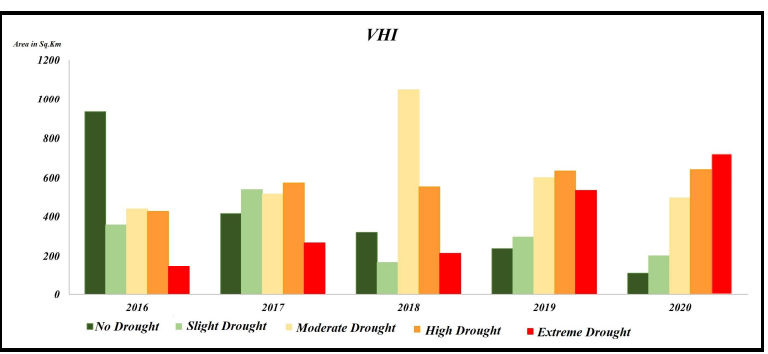

Figure 11: Graphical representation of VHI classes for consecutive years (2016-2020)

Eventually, the spatio-temporal analysis of the VHI results exemplifies that the area of healthy vegetation and no drought category is rapidly decreased from 934.29 to 107.83 sq.km, whereas the extreme drought category is increased from 146.30 to 722.36 sq.km and rest of the classes follows uneven pattern across the years (Figure 11). These are the sign of environmental degradation as the area of healthy vegetation is extremely dropped to $107.83 \mathrm{sq} . \mathrm{km}$. Therefore, It is mainly to the inadequate rainfall in the Kodavanar watershed. The results of VHI has been compared with the PCI and SPI results (Figure $9 \& 10$ ). It shows that the rainfall is uneven and insufficient in recent years and that impacts the vegetation growth and impedes the vegetation stress and agricultural drought in the study region. Further, the VHI and SPI values are correlated and shown in Figure 12. This correlation has been done for all the years from 2016-2020 and represented in graphical format. In the figure 12, the attributes of $a, b, c$ and d denote different categories (i.e., (a) denotes moderate vegetation with high to moderate wet condition (b) denotes moderate vegetation with high to moderate dry condition (c) denotes moderate to high vegetation with high to moderate dry condition (d) denotes moderate vegetation with high to moderate wet condition). Here, the $b$ and $c$ category are significant to be noted as they characterize high to moderate dry condition besides moderate to high vegetation. It is interpreted from the graph that, in the year 2016-2018, most of the correlation points are distributes in a scattered pattern in all the four categories of a, b, c and d. However, in the year 2019 and 2020 the condition has been changed and most of the correlation points have been intensified throughout the $b$ and $c$ category implies that both the SPI and VHI values have dry condition with moderate vegetation. This indicates that the watershed becomes more vulnerable condition in future. In which the northern tip and central eastern portion are the most highlighted regions of VHI as they poses highly intensified drought condition. On the other hand SPI values shows extreme dry condition in the same regions. If this condition prevails over longer period, it will affects the subsurface water system (i.e., Groundwater) and will lead to depletion of ground water.

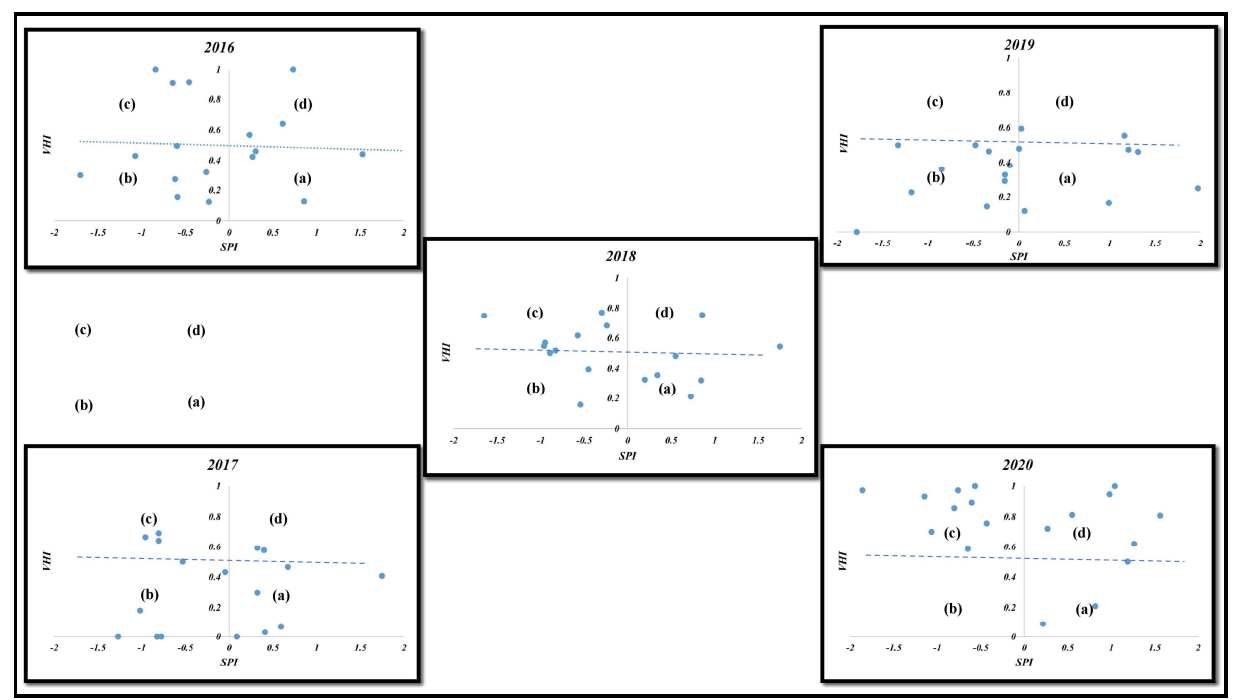

Figure12: Correlation between VHI and SPI for consecutive years (2016-2020)

\section{CONCLUSION}

The agricultural drought assessment for the study region is efficiently carried out through a cloud-based platform (GEE). Where the remote sensing indices for the study are computed effectively to portray the spatial distribution of drought intensity. However, this agricultural drought is highly influenced by meteorological factors, the meterological indicatore of PCI and SPI is derived and have been compared with the results of VHI. The study states that most of the study region are affected by extreme drought as the area of healthy vegetation and no drought classes have been decreased from 934.29 to 107.83 sq.km across the years from 2016-2020. In addition, the SPI is also showing that most of the region falls under the severe and extreme drought category. Further, the correlation results of SPI and VHI illustrates that both indices shows a parallel pattern and implying the dry condition and low vegetation in most of the regions of the Kodavanar watershed. It 
is noted that area of extreme drought class is exponentially increased from 146.30 sq. $\mathrm{km}(6 \%)$ to 722.36 sq.km (31\%). Whereas the study highlighted two vulnerable regions i.e., northern tip and central eastern portion. In the study area, the proportion of drough severity is increasing by $5 \%$ every year and if its persist for 15 to 20 years the entire region will fall under extreme drought severity class. Therefore, the highlighted regions have to be properly conserved with drought resisitant crop and proper water resource management strategies implemented by the policymakers to develop the watershed sustainably.

\section{ACKNOWLEDGEMENT}

I would like to thank my parent Department of Geography and SAP DRS-II, Bharathidasan University for their support. The authors are thankful to anonymous reviewers for their critical comments and valuable suggestion.

\section{REFERENCES}

Abdul Rahaman, S., Venkatesh, R., 2020. Application of Remote Sensing and Google Earth Engine for Monitoring Environmental Degradation in the Nilgiri Biosphere Reserve and Its Ecosystem of Western Ghats, India, Int. Arch. Photogramm. Remote Sens. Spatial Inf. Sci., XLIII-B3-2020, 933-940. https://doi.org/10.5194/isprs-archives-XLIII-B32020-933-2020

Chand, R., Raju, S., 2009. Dealing with Effects of Monsoon Failures. Economic and Political Weekly, 44(41/42), 29-34. Retrieved April 16, 2021, from http://www.jstor.org/stable/25663677.

Chander, G., Markham, B.L., Helder, D.L., 2009. Summary of current radiometric calibration coefficients for Landsat MSS, TM, ETM+ and EO-1 ALI sensors. Remote Sensing of Environment. 113, 893-903. https://doi.org/10.1016/j.rse.2009.01.007.

Deryng, D., Conway, D., Ramankutty, N., Price, J., Warren, R., 2014. Global Crop Yield Response to Extreme Heat Stress Under Multiple Climate Change Futures. Environmental Research Letters 9, 034011: 1-13. http://dx.doi.org/10.1088/1748-9326/9/3/034011.

Khan, R., Gilani, H., 2021. Global drought monitoring with big geospatial datasets using Google Earth Engine. Environ. Sci. Pollut. Res. 28, 17244-17264. https://doi.org/10.1007/s11356020-12023-0.

Kogan, F., Gitelson, A., Zakarin, E., Spivak, L., Lebed, L., 2003. AVHRR-Based Spectral Vegetation Index for Quantitative Assessment of Vegetation State and Productivity: Calibration and Validation, in: Photogrammetric Engineering \& Remote Sensing. American Society for Photogrammetry and Remote Sensing, 899-906. https://doi.org/ https://doi.org/10.14358/PERS.69.8.899.

Livada, I., Assimakopoulos, V.D., 2007. Spatial and temporal analysis of drought in Greece using the Standardized Precipitation Index (SPI). Theor. Appl. Climatol. 89, 143-153. https://doi.org/10.1007/s00704-005-0227-z.

Patel, N.R., Yadav, K., 2015. Monitoring spatio-temporal pattern of drought stress using integrated drought index over bundelkhand region, India. Nat Hazards 77:663-677. https://doi.org/10.1007/s11069-015-1614-0.

Sazib, N., Mladenova, I., Bolten, J., 2018. Leveraging the Google Earth Engine for Drought Assessment Using Global Soil Moisture Data. Remote Sensing. 10(8):1265. https://doi.org/10.3390/rs10081265.

Siddiqui, A.R., 2004. Regional Evaluation of Desertification Hazards in the Aridlands of Western Rajasthan (an unpublished Ph. D. thesis). AMU, Aligarh, Uttar Pradesh, India, pp. 221

Sobrino, J.A., Jimenez-Munoz, J.C., and Paolini, L., 2004. Land surface temperature retrieval from Landsat TM 5. Remote Sensing of Environment., 90, 434-440. https://doi.org/10.1016/j.rse.2004.02.003.

Sun, B., Qian, J., Chen, X., and Zhou, Q., 2020. Comparison and Evaluation of Remote Sensing Indices For Agricultural Drought Monitoring Over Kazakhstan, Int. Arch. Photogramm. Remote Sens. Spatial Inf. Sci., XLIII-B3-2020, 899-903, https://doi.org/10.5194/isprs-archives-XLIII-B3-2020-8992020 .

Unganai, L.S., Kogan, F.N., 1998. Drought Monitoring and Corn Yield Estimation in Southern Africa from AVHRR Data. Remote Sens. Environ. 4257, 219-232. https://doi.org/https://doi.org/10.1016/S0034-4257(97)00132-6.

Venkatesh, R., Abdul Rahaman, S., Jegankumar, R., and Masilamani, P., 2020. Eco-Environmental Vulnerability Zonation in Essence of Environmental Monitoring and Management, Int. Arch. Photogramm. Remote Sens. Spatial Inf. Sci., XLIII-B5-2020, 149-155. https://doi.org/10.5194/isprsarchives-XLIII-B5-2020-149-2020.

Wilhite, D. A., Svoboda, M.D., Hayes, M. J., 2007. Understanding the complex impacts of drought: a key to enhancing drought mitigation and preparedness. Water Resour Manag 21:763-774. https://doi.org/10.1007/s11269-006-9076-5.

Yu, H., Li, L., Liu, Y., Li, J., 2019. Construction of Comprehensive Drought Monitoring Model in Jing-Jin-Ji Region Based on Multisource Remote Sensing Data. Water 11, 1-17. https://doi.org/https://doi.org/10.3390/w11051077. 